\title{
ADVANCED TURBINE DESIGN FOR COAL-FUELED ENGINES
}

\section{DOE CONTRACT DE-AC21-89-MC-26052}

UTRC R91-970023-6

TOPICAL REPORT

TASK 1.6

TASK 1.7

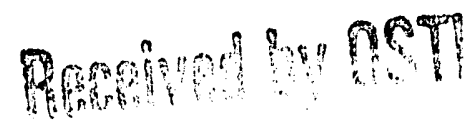

JULY 17, 1992

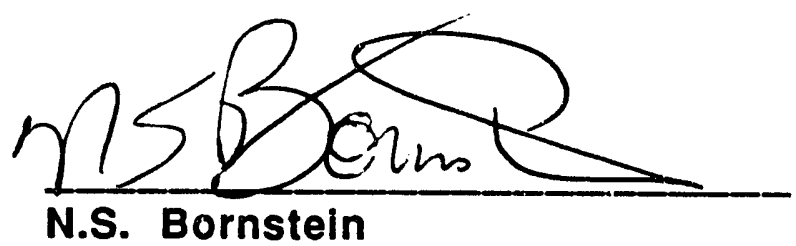

Chief, Materials Processing Research
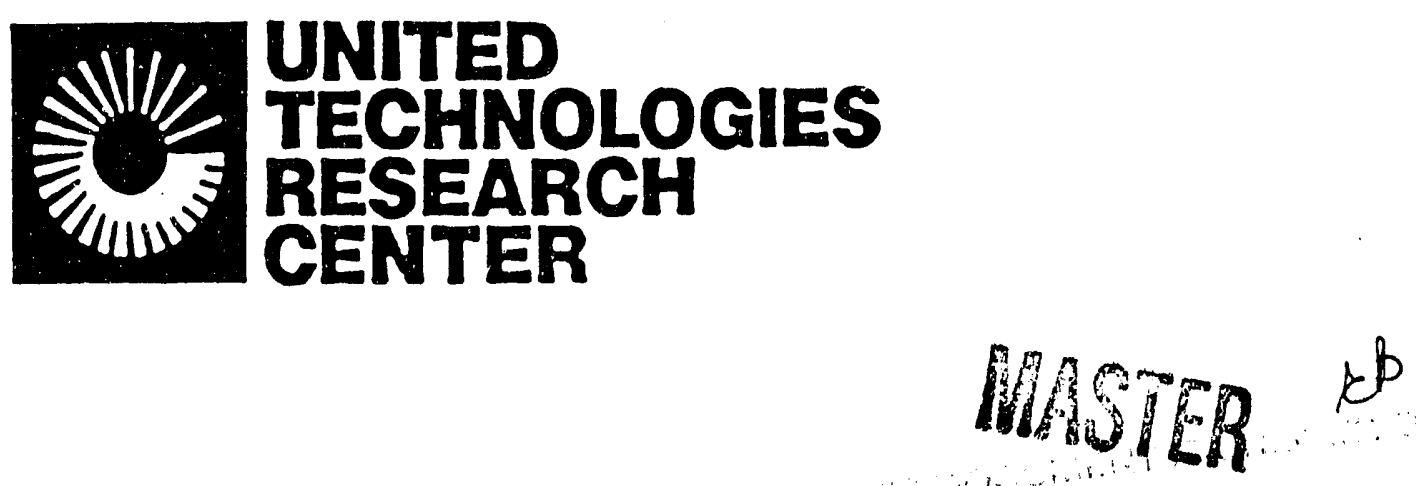


\section{TASK 1.6}

\section{EXECUTIVE SUMMARY}

The objective of this task is to perform a technical assessment of turbine blading for advanced second generation PFBC conditions, identify specific problems/issues, and recommend an approach for solving any problems identified. A literature search was conducted, problems associated with hot corrosion defined and limited experiments performed.

(1) The conditions that favor sulfidation corrosion are present in PFBC turbines. Sulfidation corrosion occurs in industrial, marine and aircraft gas turbine engines and is due to the presence of condensed alkali (sodium) sulfates. The principle source of the alkali in industrial, marine and aircraft gas turbine engines is sea salt crystals. The principle source of the sulfur is not the liquid fuels, but the same ocean born crystals. Moreover deposition of the corrosive salt occurs primarily by a non-equilibrium process. Sodium will be present in the cleaned combusted gases that enter the PFBC turbine. Although equilibrium condensation is not favored, deposition via impaction is probable.

(2) Accelerated oxidation associated with the presence of chlorine or chlorides is not anticipated. Marine gas turbines operate in sodium chloride rich environments without experiencing the accelerated attack noted in coal fired boilers where condensed chlorides contact metallic surfaces. Gaseous mixtures of sodium chloride and air are reported to mitigate sufidation corrosion.

(3) Calcium sulfate can be an aggressive corrodent. The sulfates of calcium and magnesium are the products of the reactions used to control sulfur. Based upon industrial gas turbine experience and laboratory tests, calcium and magnesium sulfates are, at temperatures up to $1500^{\circ} \mathrm{F}\left(815^{\circ} \mathrm{C}\right)$, relatively innocuous salts. In this study it is found that at $1650^{\circ} \mathrm{F}\left(900^{\circ} \mathrm{C}\right)$ and above, calcium sulfate becomes an aggressive corrodent.

(4) The ternary sulfates of calcium. magnesium and sodium are very agaressive corrodents. Calcia and magnesia are used to capture the oxides i sulfur. The presence of sodium and the formation of sulfates can lead to the formation of corrosive salts which will attack turbine components.

(5) The anticipated materials for advanced DOE engines are the high temperature single crystal alloys used in advanced aircraft gas turbines. A 
noteworthy observation is that the single crystal alloy appears to be more resistant to the combined calcium-magnesium-sodium sulfate corrosion that the industrial alloys developed to resist sulfidation corrosion. The resistance of the current families of coatings with respect to the mixed sulfate corrodent is not known.

(6) Engine manufacturers establish parameters that relate turbine airfoil life with laboratory data. The data when used to rank materials is generally in agreement. However, the deposition of the corrosive salt is a non-controllable variable which differs from machine to machine. Therefore improvements in life associated with material selection by one manufacturer need not translate to another manufacturer. Improvements in life are related to the understanding of the corrosion phenomena which allows the manufacturer to intergrate operational procedures with the material selection process. Is is therefore recommended that the work outlined in the continued study which is necessary for the orderly delineation of the corrosion mechanism and assessment with respect to lifetime based upon laboratory tests, be continued.

\section{LITERATURE SURVEY}

\section{Introduction}

Hot corrosion is defined as the accelerated rate of oxidation of turbine materials associated with the presence of oxidizing agents other than oxygen and nitrogen. Vanadic and sulfidation corrosion are the terms used to describe the accelerated oxidation due to the presence of vanadium oxides and alkali salts, respectively. Alkali salts are present not only in the fuel but are also present in the air. The presence of vanadium rich oxides is not anticipated in second generation PFBC equipment and therefore is not considered in this study.

\section{Baskground}

\section{A. Description}

Sulfidation corrosion is the rapid oxidation of gas turbine components associated with sodium sulfate. It is characterized by the presence of a nonprotective oxide scale separated from the unaffected matrix by a zone containing sulfide precipitates. The corrosion is reproduced in the laboratory by application of sodium sulfate and subsequent exposure at elevated temperatures. The corrosion phenomena is readily monitored from periodic weight changes and can be described in three steps (fig 1). The initial oxidation behavior is similar to that of simple oxidation in which the specimen 
slnwly gains weight as if the salt was not present. This is the "incubation period", (step 1) in which the corrosive salt is separated from the alloy matrix by a protective oxide scale. Once the scale is penetrated, chemical reactions occur which results in the rapid gain in weight as the matrix reacts with oxygen to form oxides. This second step is of short duration and is followed by the third step in which the rate of oxidation of the salt coated material slowly decreases with increasing time.

\section{B. Mechanism}

The corrosion community initially believed that the accelerated rate of oxidation associated with sulfidation corrosion is related to the preferential oxidation of the sulfur rich phases. Danek (1) reported in a review paper that sulfur acted as the "promotor and propagator" of hot corrosion attack. Hancock (2) related the attack to the transformation of chromium rich sulfides to nickel rich sulfides, while Seybolt $(3,4)$ related the accelerated rates of oxidation to the preferential oxidation of the intergranular sulfides. Davin et al (5), Spengler and Viswanathan (6) and Erdos (7) examined the kinetics of the gaseous sulfurmetal reactions as a function of temperature and concentration.

Bornstein and DeCrescente (8) were among the early investigators to demonstrate that the rapid rate of oxidation associated with sulfidation corrosion is related to the the inability of the substrate to form a protective oxide scale and is not due to the oxidation of the sulfur rich phases. Their work demonstrated that the sulfur rich phase is the signature that sodium sulfate was present, figure 2.

The oxide ion theory first proposed by Bornstein et al was initially modified by Goebel et al (9). They proposed that the fused alkali salt exhibits both basic (type 1) and acidic (type 2) characteristics which are related to the partial pressure of sulfur oxides in the corrosion environment. Type 1 is generally associated with high temperature corrosion while Type 2 is associated with lower temperature corrosion. Type 2 is most prevalent at temperatures between 1200 and $1475^{\circ} \mathrm{F}\left(650\right.$ and $\left.800^{\circ} \mathrm{C}\right)$ and requires a significant pressure of $\mathrm{SO}_{3}$ in the gas phase. Meier (10) reports that there is general agreement that Type 1 corrosion propagates via basic fluxing. Although, the propagation mode for Type 2 is still rather uncertain, Hwang (11) most recently reports that even at $1300^{\circ} \mathrm{F}\left(700^{\circ} \mathrm{C}\right)$ the oxide scale dissolves by basic fluxing. This data further reinforces the original oxide ion mechanism which is shown schematically in figure 3.

In figure 3, the corrosive salt, in equilibrium with exide ions (O"), is separated from the matrix by an alumina rich oxide scale. The oxide ions react with and 
dissolve alumina. This time dependent reaction corresponds to the incubation period (step 1). Once the oxide is penetrated, another chemical reaction occurs between the salt and the substrate. The products are oxides, sulfides and more oxide ions which prevent the reformation of a protective oxide scale, (step 2). In step 3, the rate of oxidation of the alloy decreases with the dilution of the oxide ion concentration.

\section{Chlorides}

Although sodium chloride is the principle constituent of sea salt, and sea salt is the precursor for sulfidation corrosion; chloride is rarely found in the deposits associated with sulfidation corrosion. Stringer (12) reports that there is a long and continuing controversy about the role of chloride in sulfidation corrosion. Most deposits contain no detectable chloride. Small quantities of chloride have been reported in the deposits removed from marine engines, however it is unclear if the source of the chloride is self contamination. According to Tschinkel (13) sodium chloride is not stable under gas turbine conditions. Not only are the partial pressures of sodium hydroxide and hydrogen chloride much greater than that of sodium chloride, but sulphation, (the chemical formation of sulfur compounds), further decreases the stability of sodium chloride, as shown by the work of Stearns et al (14).

The simultaneous attack of ferrous and nickel base alloys by condensed alkali sulfates and chlorides is well documented $(15,16,17)$. However the deleterious effect is almost always associated with reduced or lowered partial pressures of oxygen, a condition never observed in the highly oxidizing environment of the industrial, marine or aircraft gas turbine engine.

Few studies have been made on the effect of gaseous halides with respect to the oxidation of high temperature structural alloys. Smeggil et al (18) found that sodium chloride vapors accelerate the rate of oxidation of a model nickel base superalloy. The same authors also reported that sodium chloride vapors affect the growth of chromia and alumina scales, the principle oxides formed on gas turbine components (19). However sodium sulfate attenuates the corrosivity of gaseous sodium chloride. Sodium chloride vapors were found to mitigate the corrosive effect of sodium sulfate and conversely, the attack of chromia forming scales by gaseous sodium chloride was retarded by sodium sulfate. Thi's, based upon the available data and current engine experience, gaseous sodium chloride in the presence of alkali sulfates is relatively innocuous. The conditions necessary to produce condensed sodium chloride in the turbine section of industrial, marine and aircraft gas turbine engines are not encountered. 


\section{Life Assessment}

\section{Alloys and Coatings}

The early materials for gas turbine blading were based on the the heater alloy $\mathrm{Ni}-20 \mathrm{Cr}$. Chromium imparted both strength and oxidation resistance. It was soon discovered that the desired mechanical properties of the alloy were significantly increased by the precipitation of an ordered fcc phase formed by the addition of titanium and aluminum. In order to increase the concentration of aluminum and titanium it was necessary to decrease the concentration of chromium in the alloy. In the period from the fifties to late sixties, efforts were concentrated on improving mechanical properties and oxidation and corrosion resistance was achieved through the use of coatings. The introduction of refractory metals and carbides further increases the strength of the alloys. Further improvements in mechanical properties were realized through control of grain boundaries. Weakness associated with grain boundaries were alleviated by the development of directionally solidification and single crystal alloys. A comparison of stress-rupture properties of conventional, directionally solidified and single crystal alloys are shown in figure 4 and the chemical composition of typical alloys is shown graphically in figure 5 .

Coatings are used to extend the useful life of gas turbine components. Coatings are composed principally of the elements nickel, (cobalt) chromium and aluminum. Several studies have been made of the oxidation behavior of the $\mathrm{Ni}-\mathrm{Cr}-\mathrm{Al}$ system and an oxide map (21) is reproduced in figure 6 . Alumina is the preierred oxide for high temperature performance, because it rapidly forms and slowly thickens. In general chromium in solution decreases the critical concentration of aluminum necessary to form the alumina scale. Chromia scales are not satisfactory at temperatures above $1650^{\circ} \mathrm{F}\left(900^{\circ} \mathrm{C}\right)$ because they tend to volatilize (22). However chromia is the preferred scale for resistance to sufidation corrosion.

The coatings used to protect the superalloys are generally divided into the groupings of diffusion and overlay. The aluminides are diffusion coatings and are based upon the enrichment of the surface of the alloy with aluminum in order to form the intermetallic compound NiAl. In general the oxidation and hot corrosion resistance of these coatings are dependent upon the chemistry of the underlying alloy. Processes have been developed to modify the intermetallic compound by the addition of precious metals such as platinum, paladium and rhodium. Theses coatings are more costly than the simple aluminides but often exhibit improved resistance to sulfidation corrosion. The overlay coatings typified by the MCrAlY series(M= $\mathrm{Fe}, \mathrm{Co}, \mathrm{Ni}$ or combinations thereof) offer a wider range of flexibility. Oxidation and hot corrosion can be varied to meet 
various requirements. Although few studies have been performed under rigorously controlled conditions, the curve shown in figure 7 is a compilation. of available data (23) which shows the relative resistance to sulfidation corrosion as a function of chromium content.

\section{Salt Deposition}

The concept of an allowable alkali content is probably based upon the assumption that the corrosive sodium sulfate salt is produced from the reaction between sodium salts and the oxides of sulfur. Sulfur is a constituent of petroleum base fuels and its concentration can vary from parts per million to weight percent. Sodium is a principle constituent of the sea-salt crystals born at the ocean-air interface which enter the gas turbine engine with the intake air. Based upon meterological studies, sea salt crystals travel inland more than 200 miles on the prevailing winds (24). Salt water is also a common contaminant of petroleum fuels transported by barge or ship.

DeCrescente and Bornstein (25) were among the first to demonstrate that gaseous mixtures of sodium sulfate and air are relatively innocuous with respect to gas turbine engine materials. However the condensed salt is very corrosive. Numerous studies have been conducted concerning the formation, vapor pressure, and condensation of sodium sulfate in gas turbine engines (2631).

There is sufficient evidence to conclude that the corrosive sodium sulfate salt is deposited onto gas turbine components by non-equilibrium processes $(32,33)$. In a EPRI supported study (34) it is shown that the thin films of salt adhering to the components of the low compressor are similar in composition to that of sea salt. However the composition of the salts adhering to the latter compressor stages is of the same composition as the salts found on the turbine components that suffer sulfidation corrosion. The principal constituent of the salt is sodium sulfate, Table 1. Moreover the quantity of salt adhering to the latter stages of the high compressor increases with stage number as shown in figure 8 . In the same study it is shown that the efficiency of the compressor of an industrial gas turbine engine decreases after the machine is operated during fog. The decrease in efficiency is related to the deposition of salts onto compressor components and the principal constituent of the salt is again sodium sulfate figure 9. Lastly in tests conducted at Long Island Lighting Company it is shown that the deposition of sodium sulfate onto turbine components is related to the sea breezes that bring the salt laden air into the engine figure 10 . 


\section{TABLE 1 \\ Analysis of Field Data}

\begin{tabular}{|c|c|c|c|}
\hline \multirow[t]{2}{*}{ Turbine stage } & \multicolumn{3}{|c|}{ Concentration (Ma) } \\
\hline & Sodium & Chloride & Sulfate \\
\hline 9th & 0.056 & nil & 0.1 \\
\hline 10th & 0.070 & 0.02 & 0.09 \\
\hline 11th & 0.27 & nil & 0.12 \\
\hline 12th & 18.5 & 0.2 & $90+$ \\
\hline 13th & 4.4 & 0.5 & 92 \\
\hline 14th & 9.4 & 0.7 & 53 \\
\hline 15 th & 10.6 & 1.0 & 42 \\
\hline 1st Vane & 1.01 & nil & 5 \\
\hline
\end{tabular}

The fuel is also a source of alkali. Field as well as laboratory experience verify that alkali doped fuels promote sulfidation corrosion. The experimental evidence from UTC studies supports the conclusion that the deposition of sodium sulfate from alkali doped fuel occurs via a non-equilibrium process. The calculated concentration of sodium necessary to promote equilibrium condensation of sodium sulfate at $900^{\circ} \mathrm{C}$ and 1 atmosphere is $35 \mathrm{ppm}$. The experimental data is summarized in Table 2. The data supports the conclusion that char formation assists in the deposition of the salt.

TABLE 2

Laboratory Evaluation of Sodium in Fuel ( $900^{\circ} \mathrm{C}$-atmospheric test)

\begin{tabular}{rcl} 
Time hrs & Nain fuel (pom) & Observation \\
11 & 150 & Uniform Sulfidation Attack \\
11 & 60 & Uniform Sulfidation Attack \\
6 & 65 & Uniform Sulfidation Attack \\
\hline 11 & 45 & Slight attack \\
6 & 45 & Slight Attack \\
6 & 35 & Oxidation-No Attack \\
35 & 10 & Oxidation-No Attack \\
52 & 0 & Oxidation \\
\hline
\end{tabular}

$1130^{*} \quad$ Sulfidation Attack

* low air/fuel ratio to induce char formation

In summary the data indicates that an important source of the corrosive sodium sulfate is the periodic release of the salt that accumulates on compressor 
comfanents. The fuel is also an important source of sodium, however deposition most probably occurs via a non equilibrium process .

\section{Oxidation/Corrosion Life-prediction}

Gas turbine manufacturers have developed laboratory tests designed to accelerate the oxidation or corrosion phenomena that eventually contributes to the the demise of a component. Oxidation is the principle degradation mechanism for aircraft gas turbines. High temperature cyclic oxidation tests are used to not only rank but also to measure rates of consumption or material loss. The data is compared to engine performance in order to determine life predictions.

Improvements in material performance is generally achieved through an understanding of the rate controlling process. Coatings are consumed through the loss of aluminum due to the spallation of the oxide scale. Significant improvements in the life of protective coatings is attributed to the discovery that certain reactive elements such as yttrium significantly improve oxide scale adherence.

Sulfidation corrosion is more important in industrial and marine gas turbine engines. The corrosion attack is induced in the laboratory by the application of and subsequent cyclic exposure of salt coated specimens at elevated temperatures. In general corrosion is induced in the laboratory tests within tens of hours after application of the corrosive salt. The significant improvements in the life of marine and industrial gas turbine components is once again achieved through a better understanding of how the corrosive salt deposits onto turbo machinery, and the process by which the salt defeats the normally protective oxide scale.

The major gas turbine manufacturers limit the concentration of sodium (and potassium) in the fuels. Air filtration is used to limit the quantity of air borne alkalis entering industrial and marine engines. These steps are taken in order to reduce the rate of deposition of salt onto turbomachinery. However the efficiency of the filters is dependent upon maiiy parameters. Moreover filters tend to periodically release captured solids into the air stream. Therefore the limits imposed by manufacturers are based more upon operating experience than calculations.

METC believes that the gases entering the turbine could contain up to $10 \mathrm{ppm}$ alkali, $33 \mathrm{ppm} \mathrm{HCl}$ and $144 \mathrm{ppm}$ sulfur dioxide. The alkali concentration is significantly higher than the levels established by the major gas turbine 
producers. However it does not follow that alkali sulfates will form and condense. Deposition is a necessary condition for sulfidation corrosion to occur. Of more concern is the deposition of sulfates associated with the process used to control sulfur. Alkaline earth sulfates which may also contain alkalis will be present on METC turbomachinery. The effect that these compounds can have on turbine materials needs to be determined.

\section{EXPERIMENTAL STUDIES AND RESULTS}

\section{A. Rationale}

The principal corrosive salt associated with sulfidation corrosion is sodium sulfate. The principle oxide which forms on the surface of high temperature components is alumina. The chemical interaction that occurs is reasonably well understood. However the deposits from the DOE fuel are very rich with respect to calcium and magnesium. Calcium oxide and dolminite, (a mixture of the oxides of calcium and magnesium) are used to control sulfur. One micron or finer particles are not anticipated to perform as an errodent, but are expected to deposit onto and adhere as a thin film to turbomachinery. Calcia and magnesia can react with alumina to form a host of compounds. The stoichiometry of the compounds depends upon concentration as well as temperature. Thus an area of concern is the integrity of the alumina scale.

Calcium sulfate does not suppress the melting temperature of sodium sulfate, fig 11a. Magnesium sulfate will suppress the melting temperature of sodium sulfate fig.11b, however this salt, unlike the sulfates of calcium and sodium, decomposes in the temperature range of interest to form magnesium oxide. However a stable ternary eutectic is formed in the system.

The alumina scale is the barrier that separates the hostile environment from the metallic surface. The life of turbine components is related to the rate of formation, growth and detericration of the oxide scale.

\section{B Experimental results}

In order to assess the corrosivity of calcium sulfate, a series of laboratory experiments were performed in which the surfaces of the nickel base alloy B1900 were coated with a thin film of calcium sulfate and tested at 1650, 1900 and $2100^{\circ} \mathrm{F}$. This nickel base alloy is noted for its high temperature strength, good oxidation resistance and poor resistance to hot corrosion. Uncoated (calcium sulfate free) specimens served as controls. The chemical composition of the alloy and typical metallographical cross-sections are shown in fig 12. 
At $1650^{\circ} \mathrm{F}\left(900^{\circ} \mathrm{C}\right)$, no differences were noted with respect to weight changes, however the calcium sulfate coated specimens appeared discolored consistent with the formation of a chromate compound. Moreover metallographic analyses revealed the presence of sulfide precipitates beneath the oxide scale. At $1900^{\circ} \mathrm{F}\left(1040^{\circ} \mathrm{C}\right)$ and at $2100^{\circ} \mathrm{F}\left(1150^{\circ} \mathrm{C}\right)$ the calcium sulfate coated specimens experienced considerable losses in weight. The weight loss is reported in figure 13 as loss in cross-sectional thickness. The sulfide precipitates observed in the metallographical cross-sections are not consistent with classical sulfidation corrosion. Based upon the results further experiments were performed with the alloys $I N-738, I N-792$ and PW-1480.

As previously noted, the first two alloys are representative of the alloys currently employed in industrial gas turbines, and the third alloy is representative of the newer family of single crystal alloys used in advanced aircraft gas turbine engines. Each alloy was coated with, (a) sodium sulfate, (b) calcium sulfate and (c) a mixture of sodium, calcium and magnesium sulfates in the ratios consistent with eutectic formation. The salt coated specimens were exposed at $1900^{\circ} \mathrm{F}$ and the experimental results are summarized in figure 14.

The sulfidation behavior is consistent with published data. The chromium rich alloy $\mathrm{IN}-738$ is most resistant followed by $\mathrm{IN}-792$ and the least resistant is the alumina forming, chromium poor single crystal alloy PW-1480. Note also that the alumina forming PW-1480 alloy is least affected by the calcium sulfate. The poorer performance of the $\mathrm{IN}-738$ and $\mathrm{IN}-792$ may be related to the formation of chromate salts which were observed to form on the surfaces.

It was anticipated that the eutectic salt would be corrosive. However it was not anticipated to be as aggressive as noted in figure 10. It appears to be at least 5-fold more corrosive than sodium sulfate. Equally surprising is the observation that the single crystal alloy PW-1480, which is more sensitive to sodium sulfate than the equiaxed alloys is, in this test, most resistant to the eutectic salt .

\section{RECOMMENDATIONS}

The results of the Grimthorpe tests which evaluated PFBC materials verified that alkali and calcia salts are corrosive at low temperatures and the experimental work reported herein indicates that a severe corrosion problem related to the deposition of the salts will occur as temperatures increase. The program outlined below assess the role of alkali-calcium rich salts and the magnitude of the corrosion problem . 


\section{Material Selection}

\section{A Alloys}

The oxidation and sulfidation behavior, in laboratory tests, of the coatings and alloys used in industrial and marine gas turbine alloys is known. It is recognized that the coating can influence the mechanical properties of the alloy, and that as a result of interdiffusion, the alloy influences the chemical and mechanical properties of the coating. Thus selection of a material is based upon the required mechanical properties of the substrate and the chemical and mechanical properties of the coating. The nickel base superalloys IN 738 and IN 792 are noted for both their strength and inherent sulfidation resistance and are the alloys most widely used in industrial and marine gas turbine engines. PW 1480 is of the newer single crystal alloys to be used in industrial engines.

\section{B. Coatings}

All alloys used in the hot turbine section of industrial and marine gas turbines are coated. The coatings impart superior oxidation and sulfidation resistance and therefore prolong the life of turbine components. The recommended coatings for evaluation are the aluminides as represented by PW 73; the platinum modified aluminides widely used in industrial gas turbines as represented by RT-22 and lastly the overlay coating also widely used in industrial gas turbines represented by PW 286.

\section{TASK 1.7}

The proposed program is divided into two Phases. The objective of the first phase is to develop an understanding of the the chemistry involved between the corrosive salts and the turbine alloy systems. The objective of phase two is to develop priliminary laboratory burner rig for life prediction calculations. Both phases of the program will be performed concurrently.

\section{Phase I}

The chemistry, and morphology of the sulfidation process for the alloys and coatings proposed herein is well established and will not be repeated. The oxidation and sulfidation data base at the Research Center will serve as the base line.

In Phase 1 the chemistry and corrosion kinetics associated with calcium salts applied to the three alloys, IN 738, IN 792 and PW 1480, and an aluminide, a 
precious metal modified aluminide and a overlay coating, exposed in the temperature range from 1650 to $2100^{\circ} \mathrm{F}$, will be determined. The corrosive salts are (a) calcia, (b) calcium sulfate and (c) the mixture of sodium sulfate, calcium sulfate and magnesium sulfate which corresponds to the eutectic in the sulfate system. The data generated from chemical analyses of the corrosion products, metallographic studies and the interpretation of the kinetic data will be used to produce the corrosion model which is a necessary step in the orderly process of material modification for improved corrosion resistance.

\section{Phase II}

The burner rig sufidation data in the UTRC system will serve as the baseline for this program. No additional data is necessary. In Phase II the life of the uncoated alloys IN 738, IN 792 and PW 1480 and an aluminide, a precious metal aluminide and an overlay coated alloy will be exposed to the exit flame of a laboratory burner. The tests will be conducted at 1650 and $1900^{\circ} \mathrm{F}$. The salt solution will contain the sulfates of the elements calcium, magnesium and sodium in the ratio of the corrosive eutectic mixture. Life assessments will be determined based upon the comparative results between the specimens and prior experience. 


\section{REFERENCFS}

1. G. J. Danek, Jr., Naval Engineers J. 77 (1965) p. 859.

2. P. Hancock, Proc. First Intl. Cong. on Metallic Corr., London (Butterworks London, 1961), p. 193.

3. A. U. Seybolt and A. M. Beltran, "Hot Corrosion Problems Associated with Gas Turbines", ASTM, Special Technical Publication, No. 421 (1967), p. 21.

4. A. U. Seybolt, Trans. AIME, 242 (1968), p. 1955.

5. A. Davin, D. Coutsouradis and L. Habraken Werks and Korr, 22 (197i), p. 517.

6. C. Spengler and R. Viswanathan, Met. Trans $\underline{3}$ (1972), p. 161.

7. E. Erdos, "Deposition and Corrosion in Gas Turbines", (Applied Science Publishers, London 1973) p. 115.

8. "Investigation of Sulfidation Mechanism in Nickel-Base Superalloys." Final Report to US Naval Ship R\&D Labs, Annapolis, MD, Contract N00600-68-C-0639 by UTRC (1969).

9. J. A. Goebel, F. S. Pettit and G. W. Gowand, Met. Trans. 4 (1973), p. 26.

10. G. Meier, High Temperature Corrosion, 2, editors Streiff, Stringer, Krutenat and Callet, Published by Elsevier, London, 1989.

11. S. Y. Hwang, Ph.D. Thesis, University of Pittsburgh, 1989.

12. J. Stringer, Materials Science \& Technology, July 1987, Vol. 3, p. 482.

13. J. G. Tschinkel, Corrosion 1972, 28 pg. 161.

14. C. Stearns, F. Kohl and D. Rosner, High Temperature Corrosion, NACE-6, 1983, p. 441.

15. S. R. Saunders and S. Schlieres, High Temperature Corrosion in Energy Systems, edited by M. Rothman, AIME 1985 pg. 213.

16. M. H. Rice, M. J. McNallen and M. F. Rothman, Imid pg. 483.

17. R. C. John lbid pg. 501.

18. J. G. Smeggil and N. S. Bornstein, High Temperature Corrosion NACE-6, edited by R. Rapp, 1983, p. 310.

19. J. G. Smeggil and N. S. Bornstein, Study of the Effects of Gaseous Environments on Sulfidation Attack of Superalloys", NASA Cr-135348, Nov. 1977.

20. Decker, High Temperature Materials in Gas Turbines, Sahm/Speidel editcrs, Elsevier Publications, 1974, pg. 52.

21. G. Wallwork and A. Hed, Oxidation of Metals $\mathbf{3}$ (1971) pg. 171. 
22. High Temperature Materials in Gas Turbines, Sahm and Speidel editors Elsevier Publications 1974, pg. 283.

23. G. Goward, NACE-6 1981, pg. 553.

24. T. Sturiale, "Sea Salt Concentrations in the Atmosphere" UARL Report UAR-E209.

25 Corrosion, DeCrescente, M. \& Bornstein, N., 24(5) p127 (5/1968).

26. "Chemistry of Hot Gas Clean-Up in Coal Gasification and Combustion". MERC/SP-78/2, (1978).

27. N. S. Bornstein \& M. A. DeCrescente, Corrosion 26, 209-214(1970).

28. F. Kohl, C. Stearns and G. Fryburg, Metal-Slag-Gas Reactions and Processes, A.A. Forouks, W.W. Smeltzer (Eds), ECS Symposium Series Electrochemical Soc. Pennington (1975) pp. 649-664.

29. F.J. Kohl, G.J. Santoro, C. A. Stearns, G. C. Fryburg and D.E. Rosner, J. Electrochem Soc., 126 (1979) 1054-1061.

30. K. L. Lutha and H.S. Spacil, J. Electrochem Soc., 129 (1982) 649-656.

31. H.S. Spacil and K.L. Luthra, J. Electrochem Soc., 129, 1982 (2119-2162).

32. I. Bessen and R. Fryxell, Proc. 1st US/UK Navy Conf. on Gas Turbine Materials, Hyattsville, Md 1972, pg. 73-84.

33. C.G. McCreath, Proc. 3rd US/UK Navy Conf. on Gas Turbine Materials in Marine Environments, Session V, paper 2.

34. Protective Coatings for Utility Gas Turbines EPRI AP-2929, Final Report March 1983.

35. Alkali removal from PFBC. Lee, SH et al, Proceedings of the Sixth Annual Coal-Fueled Heat Engines by Gas Stream Clean-Up Systems, Contractors Review Meeting. DOE/METC-89/6101 (March 1989). 
FIG. 1

SULFIDATION CORROSION

CONSISTS OF THREE DISTINCT STAGES

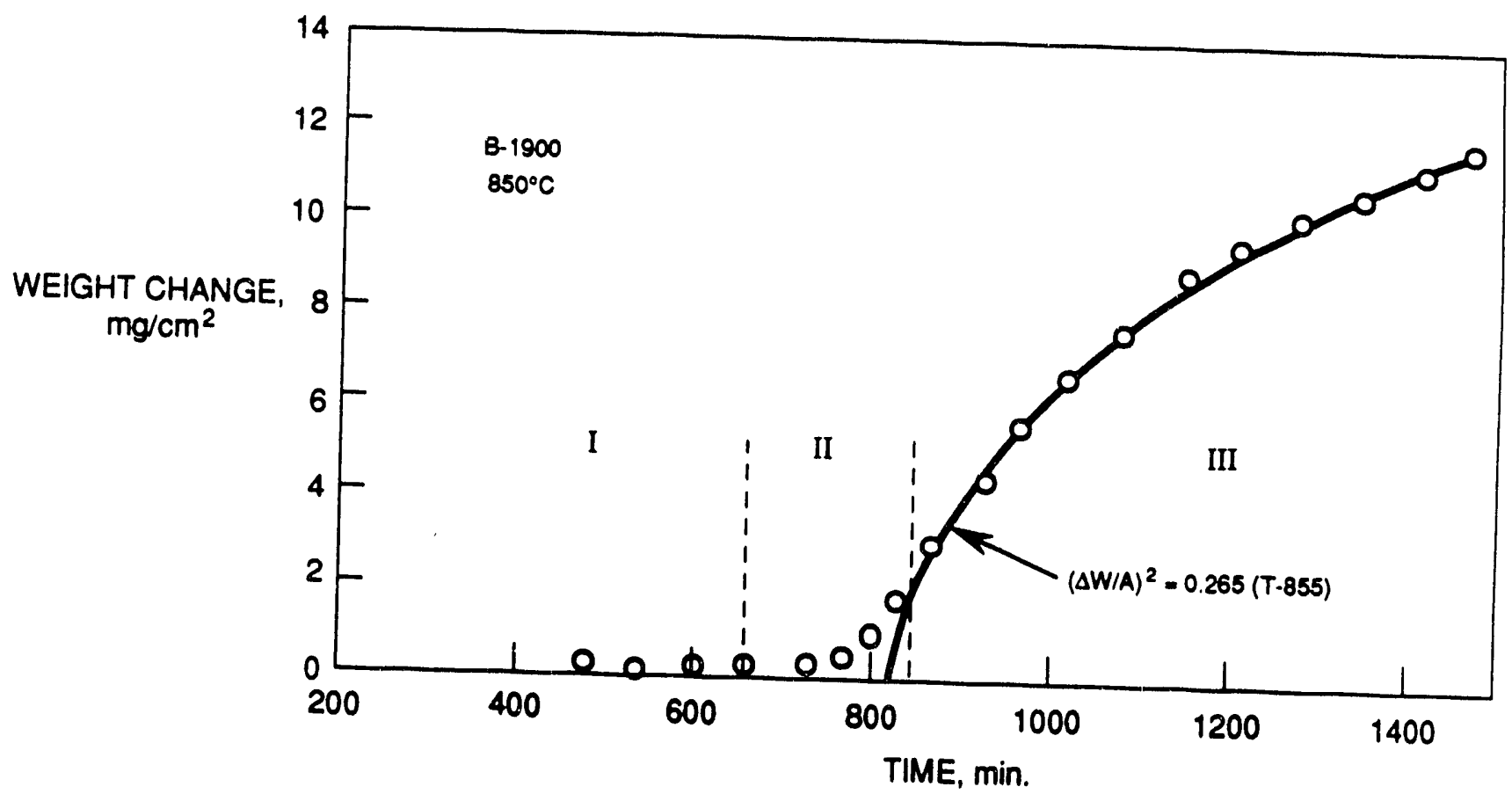


$\therefore$. .

FIG. 2

\section{SULFIDATION STUDIES}

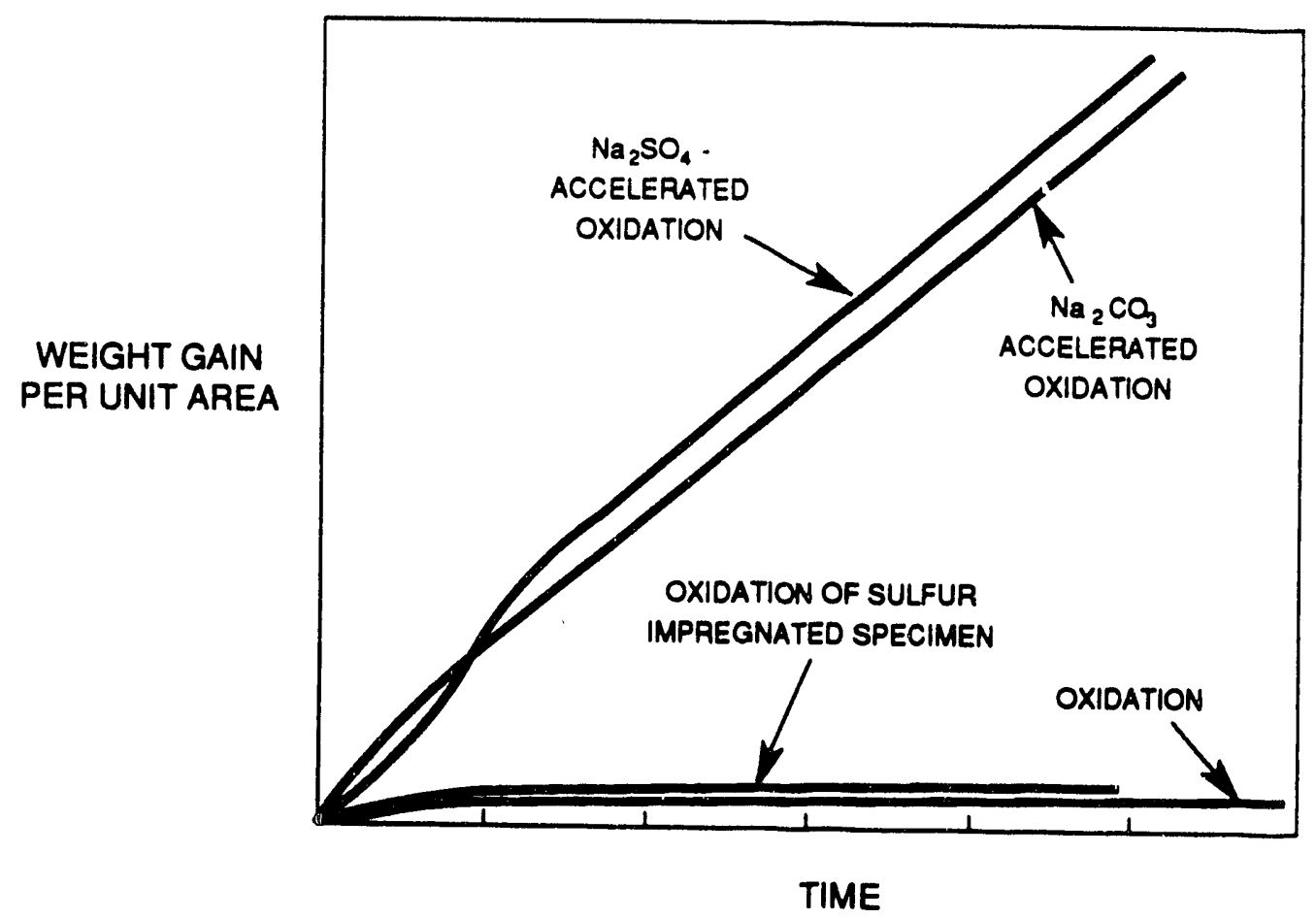


FIG. 3

THE SULFIDATION PROCESS

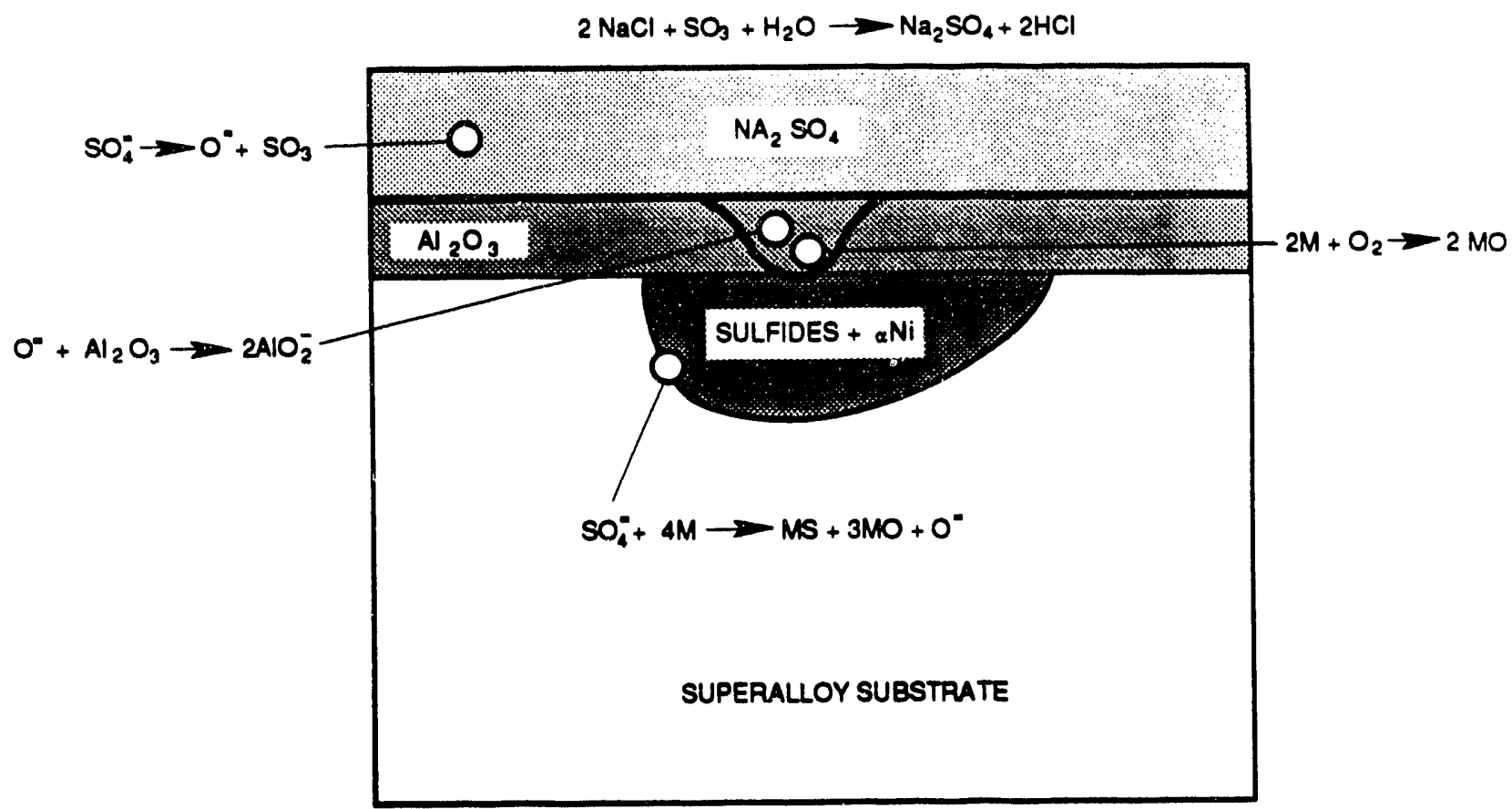


HIGH-TEMPERATURE NICKEL-BASED ALLOYS

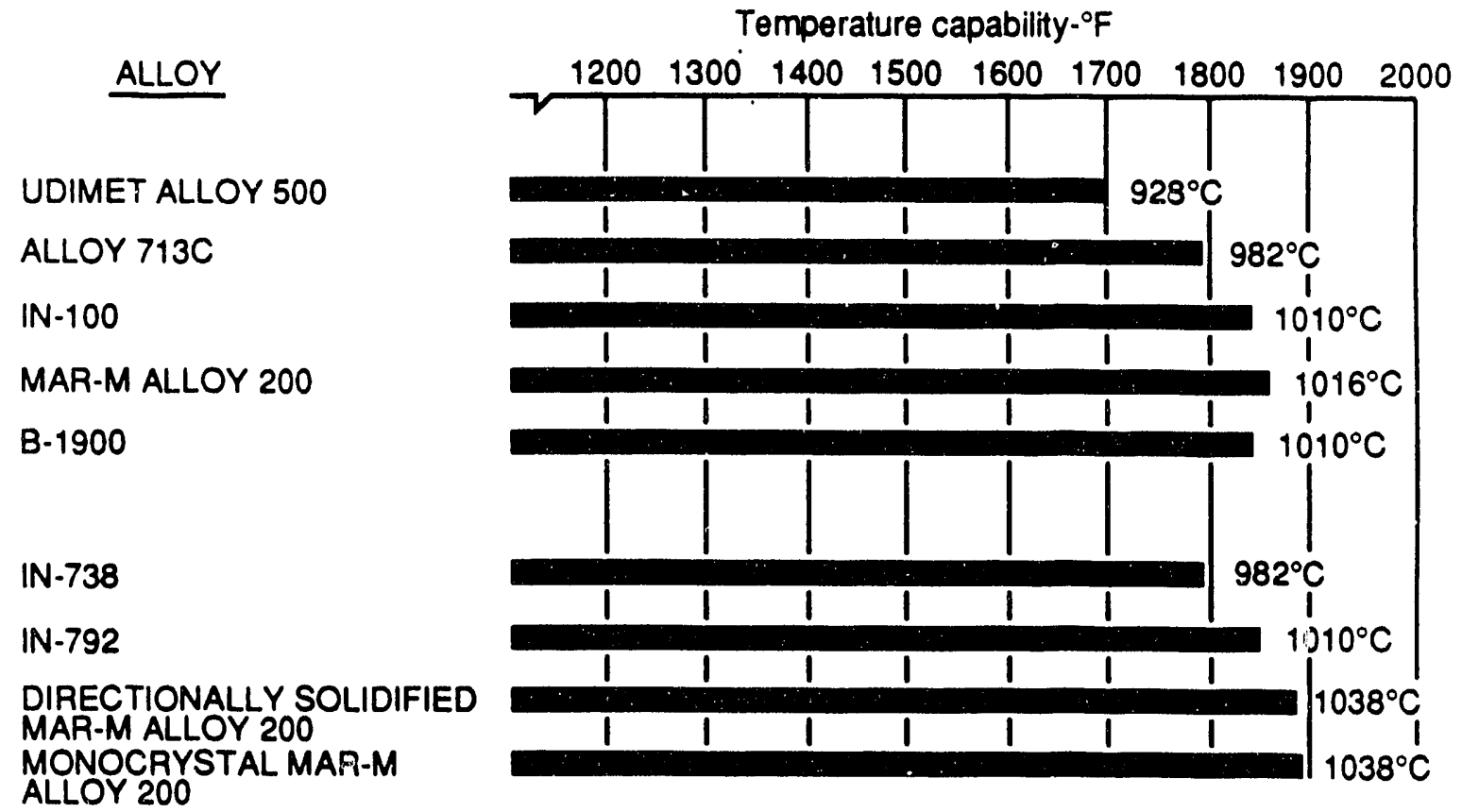

TEMPERATURE CAPABILITY=MAXIMUM TEMP. FOR 100-HR. RUPTURE LIFE AT $138 \mathrm{MN} / \mathrm{m}^{2}$ 
FIG. 5

CHEMICAL COMPOSITIONS OF CURRENT ALLOYS

(ATOMIC PERCENT)

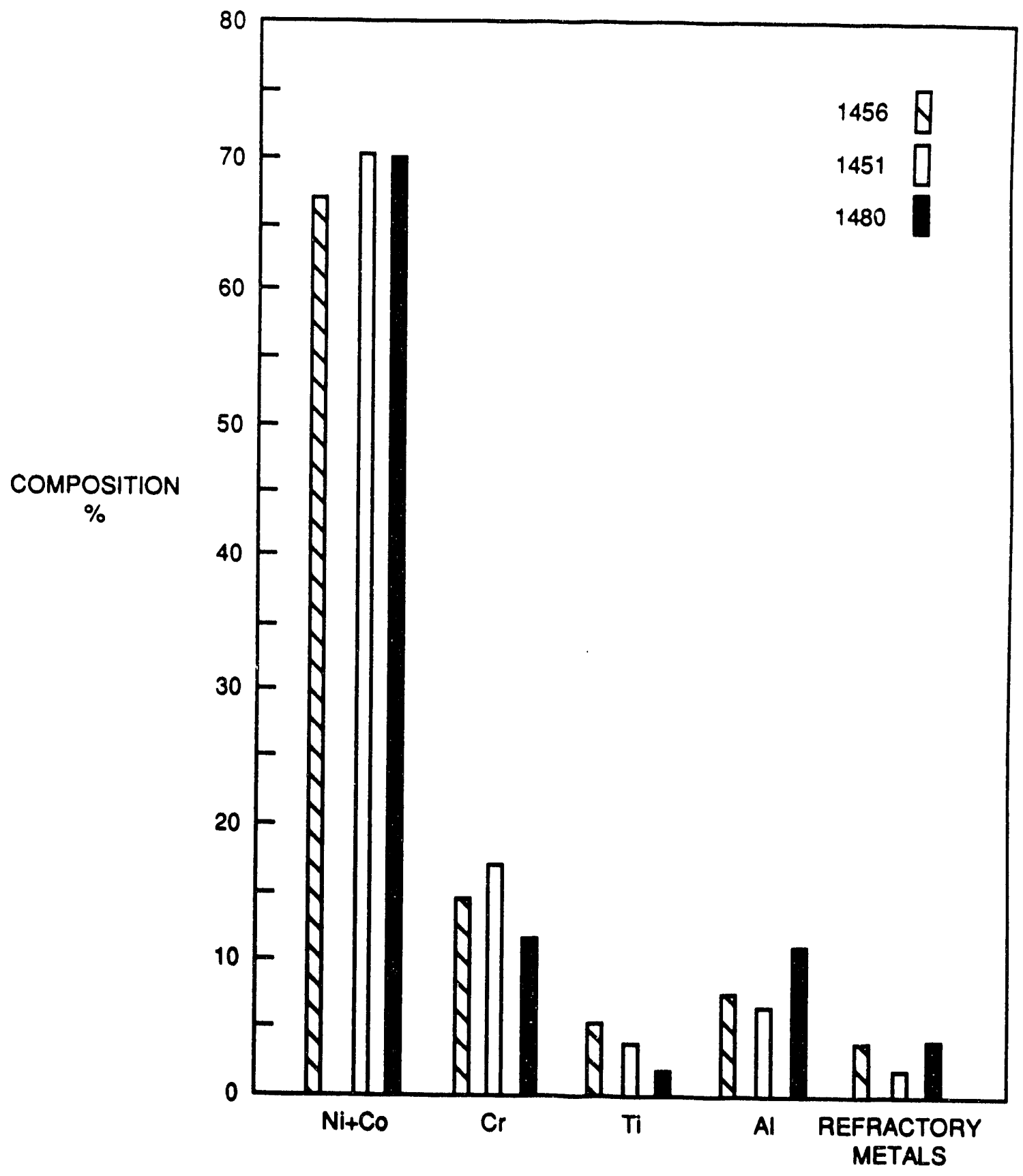


FIG. 6

\section{OXIDE MAP FOR THE TERNARY SYSTEM NI-Cr-AI AT $1000^{\circ} \mathrm{C}$}

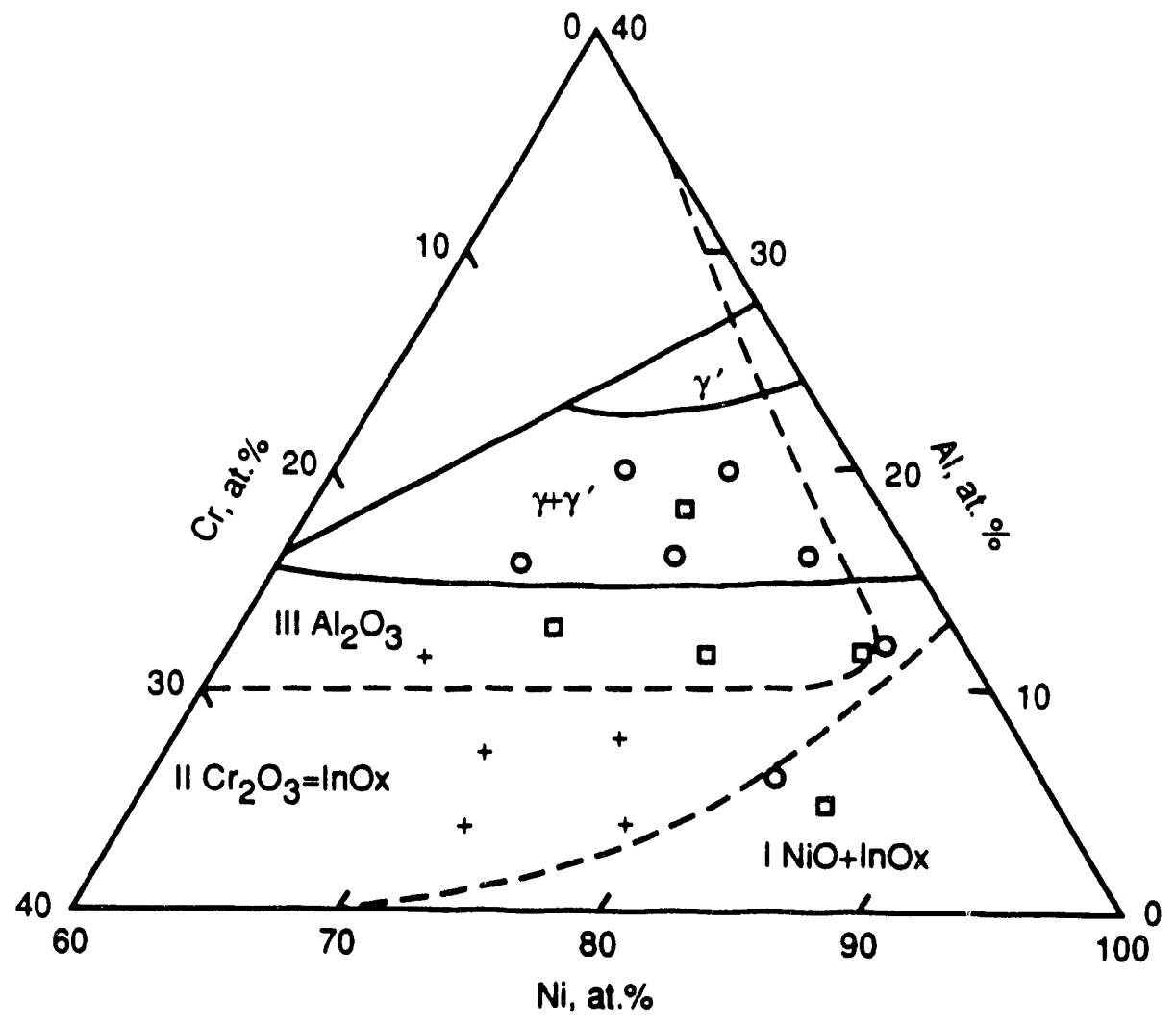


FIG. 7

DEPENDENCE OF RELATIVE RATE OF HOT CORROSION OF MCrAIY COATING ALLOYS ON CHROMIUM CONTENT; 1300F BURNER RIG TEST

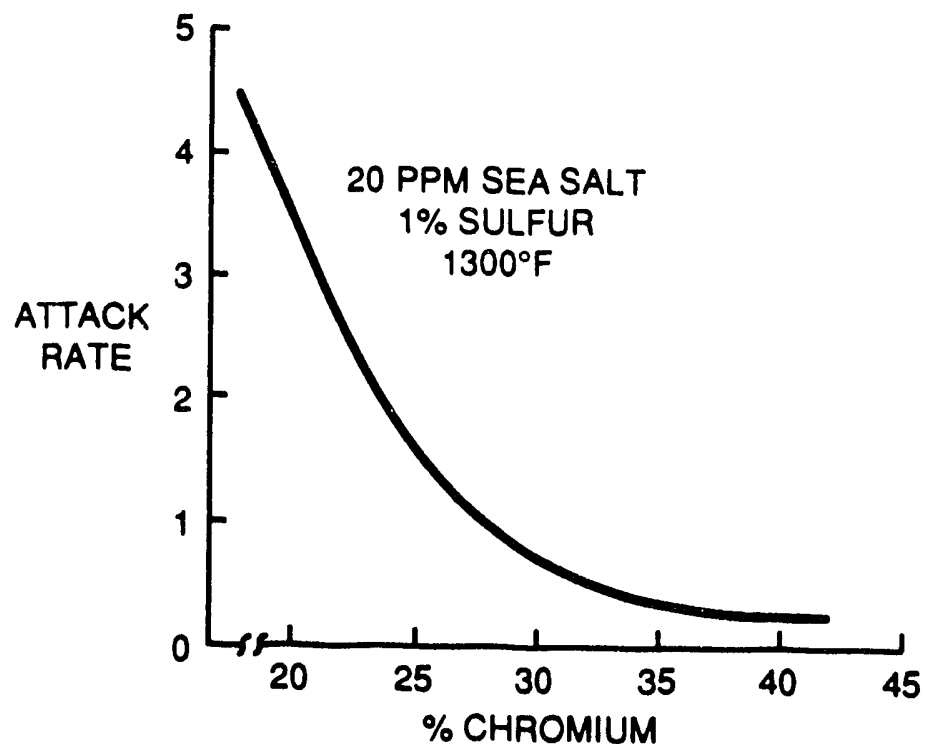


FIG. 8

\section{QUANTITY OF $\mathrm{Na}_{2} \mathrm{SO}_{4}$ VS COMPRESSOR STAGE}

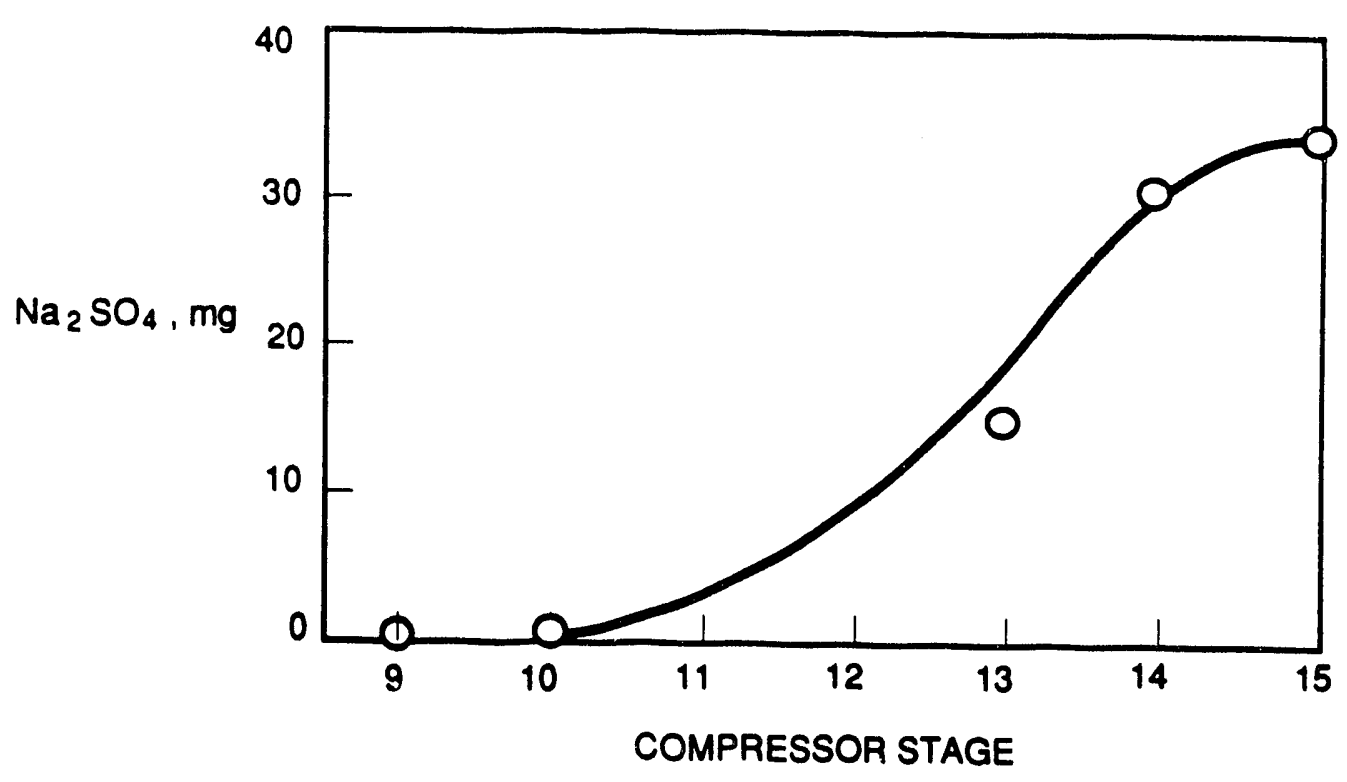


FIG.9

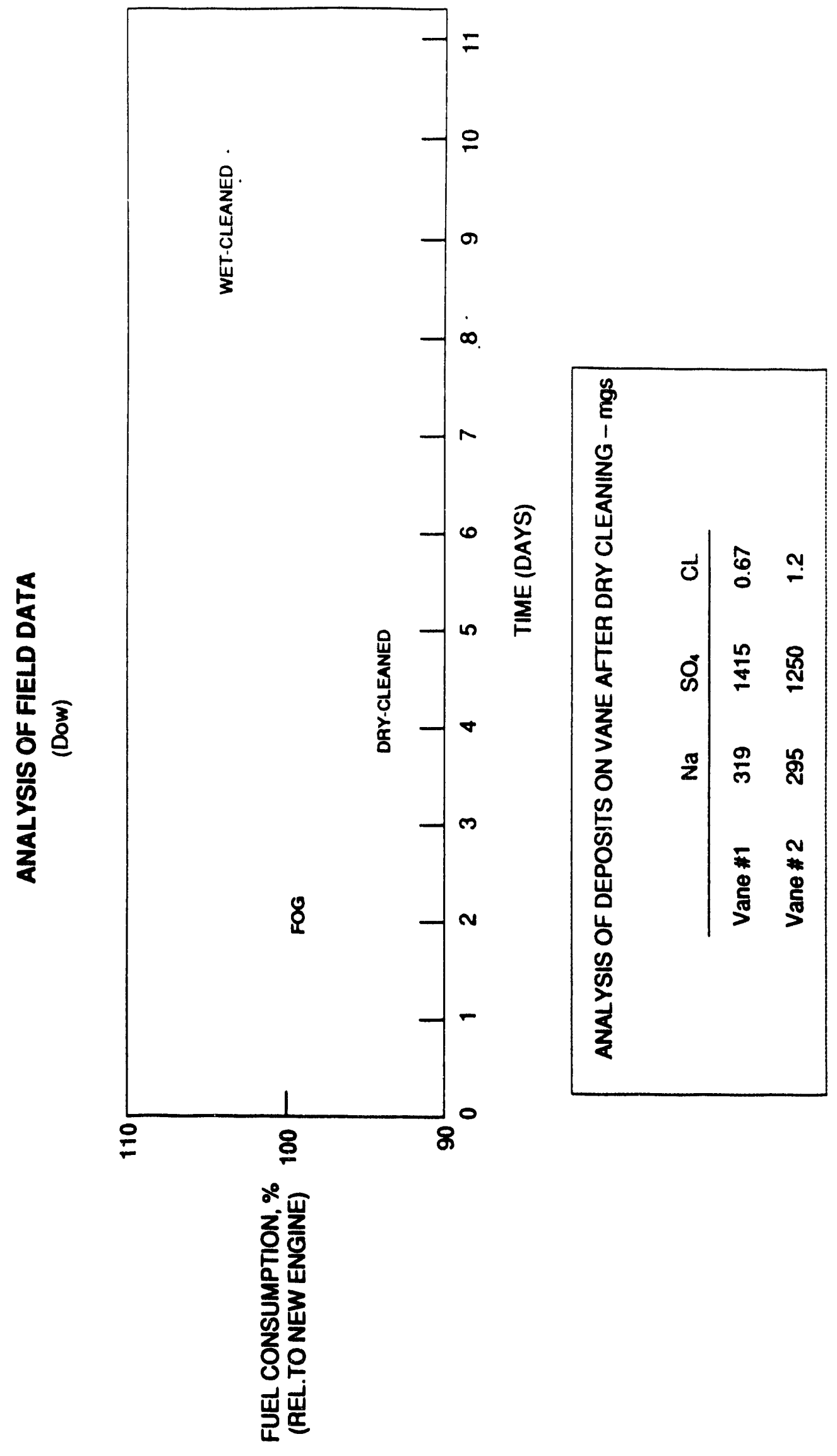


FIG. 10

DISTRIBUTION OF $\mathrm{Na}_{2} \mathrm{SO}_{4}$ VS TIME (SEASON)

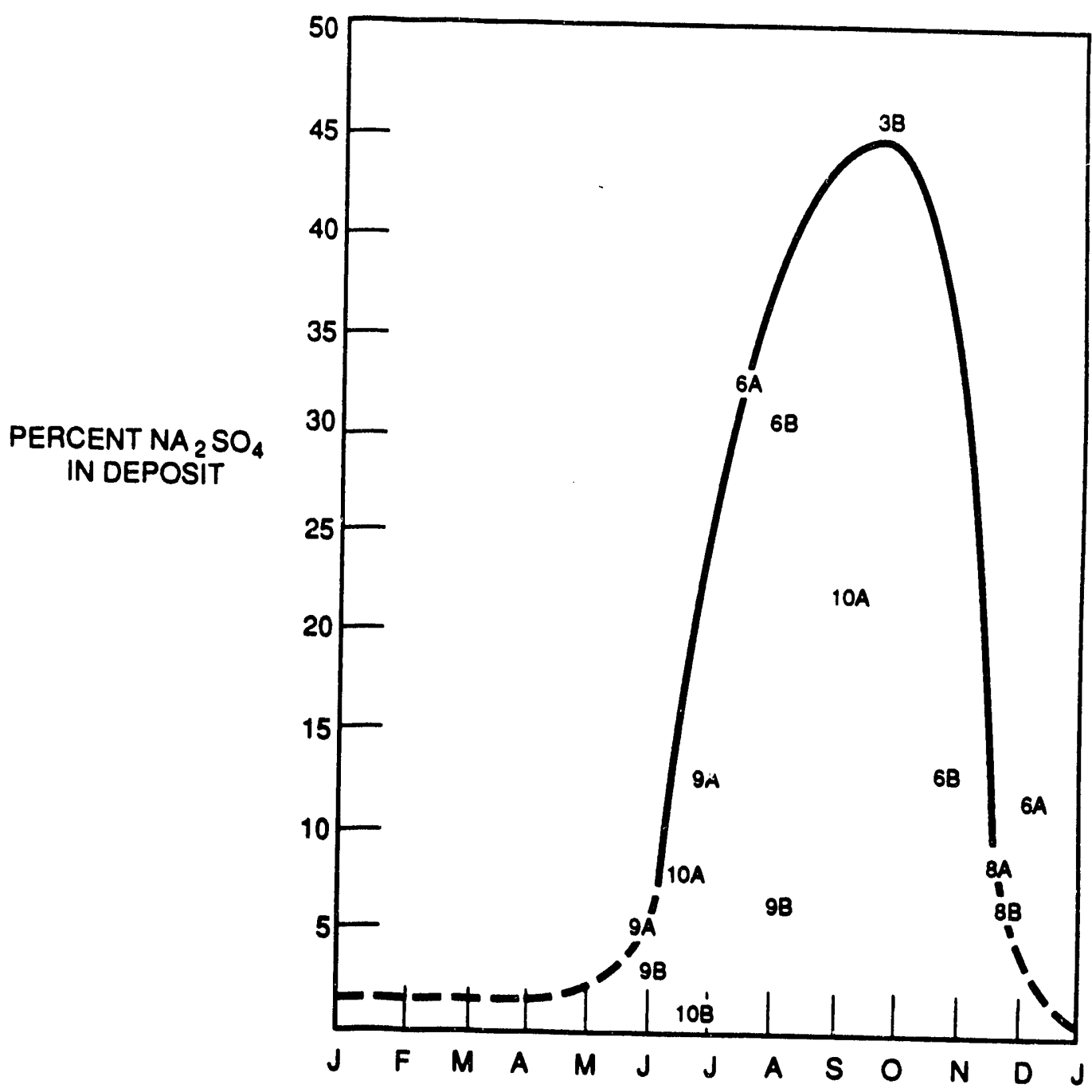


FIG. 11

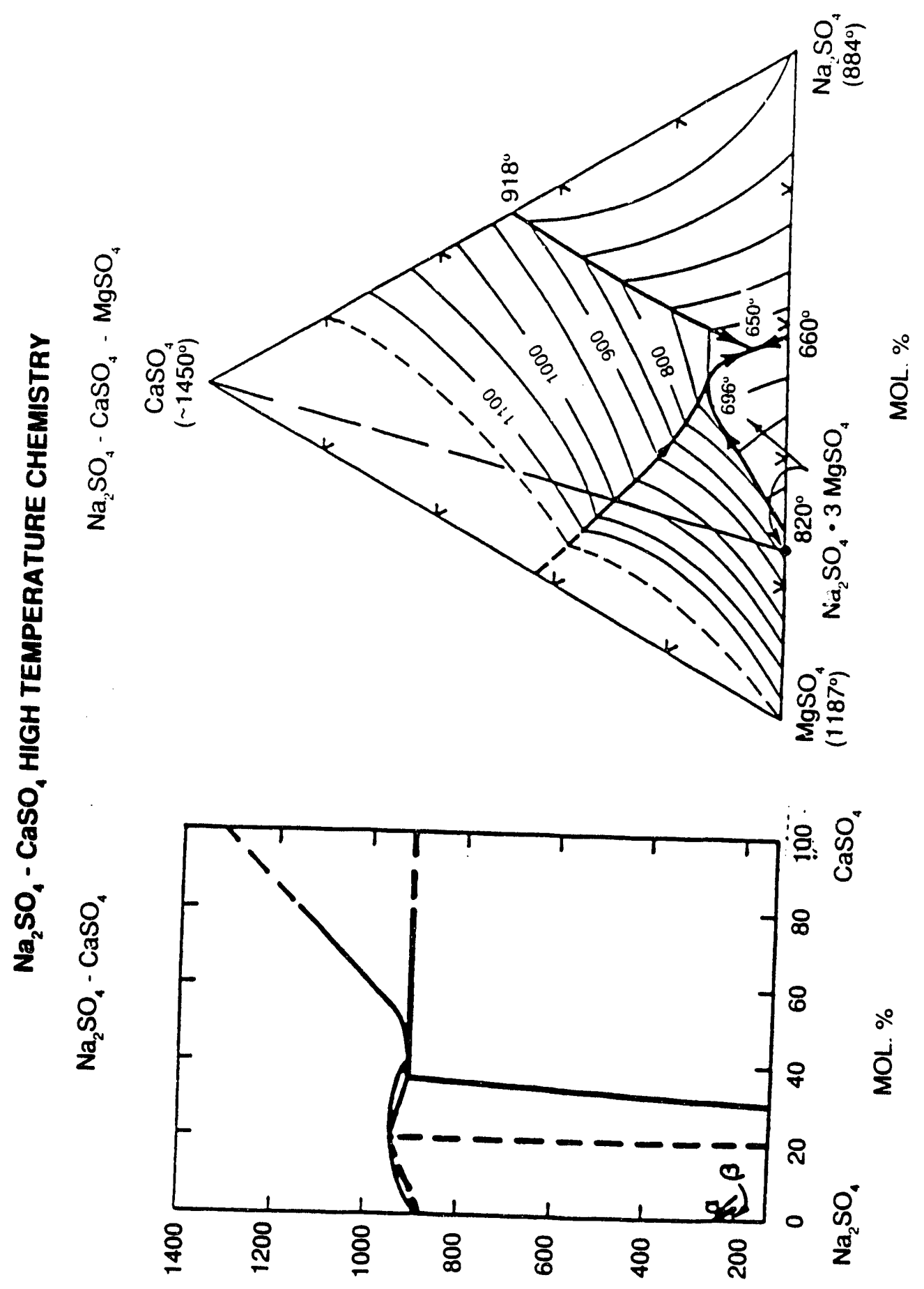



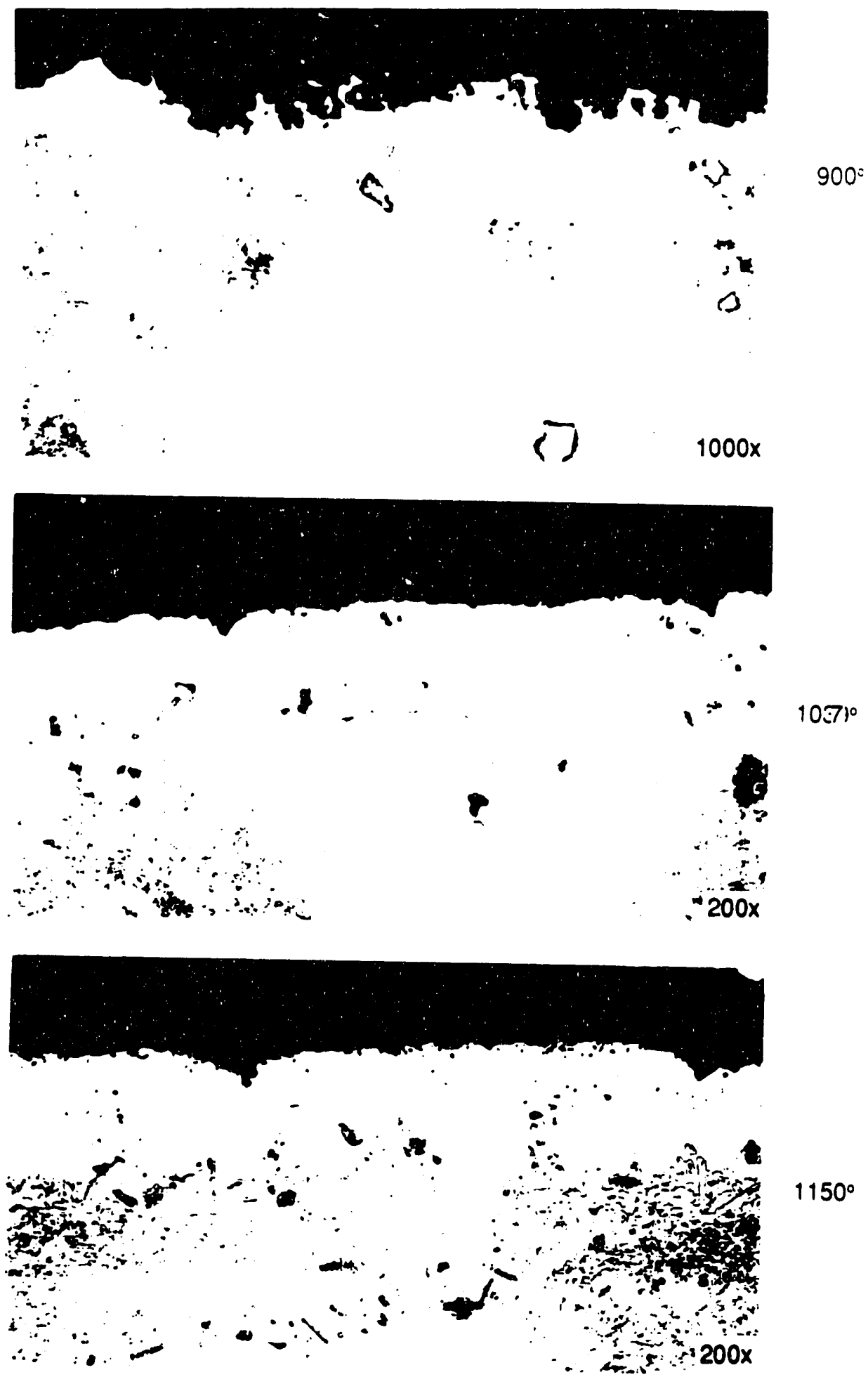
$\therefore \therefore$

FIG. 13

CaSO، ACCELERATES RATE OF OXIDATION OF NICKEL BASE SUPERALLOY (B1900)

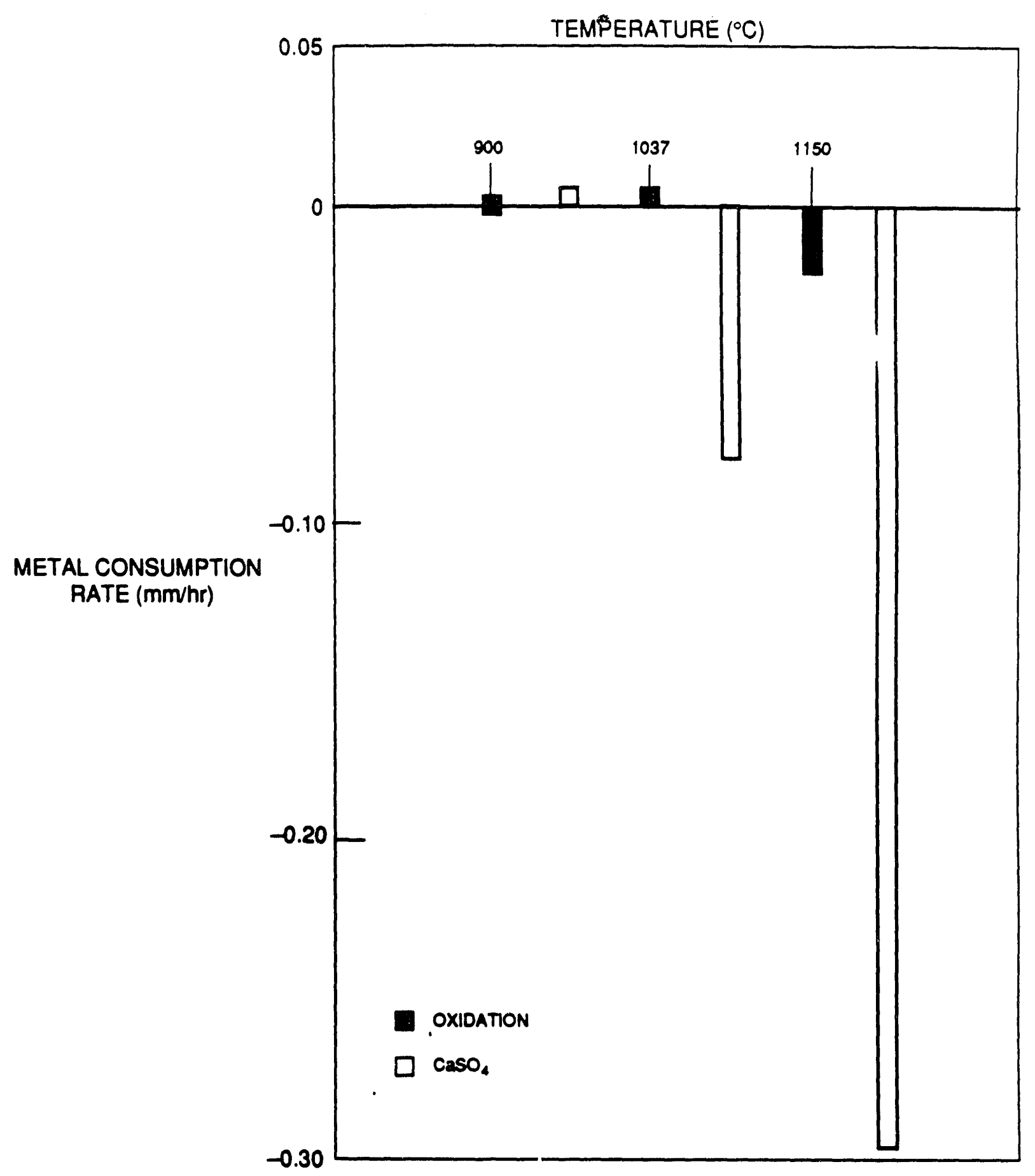


FIG. 14

1900F LAB CORROSION OF NICKEL BASE SUPERALLOYS

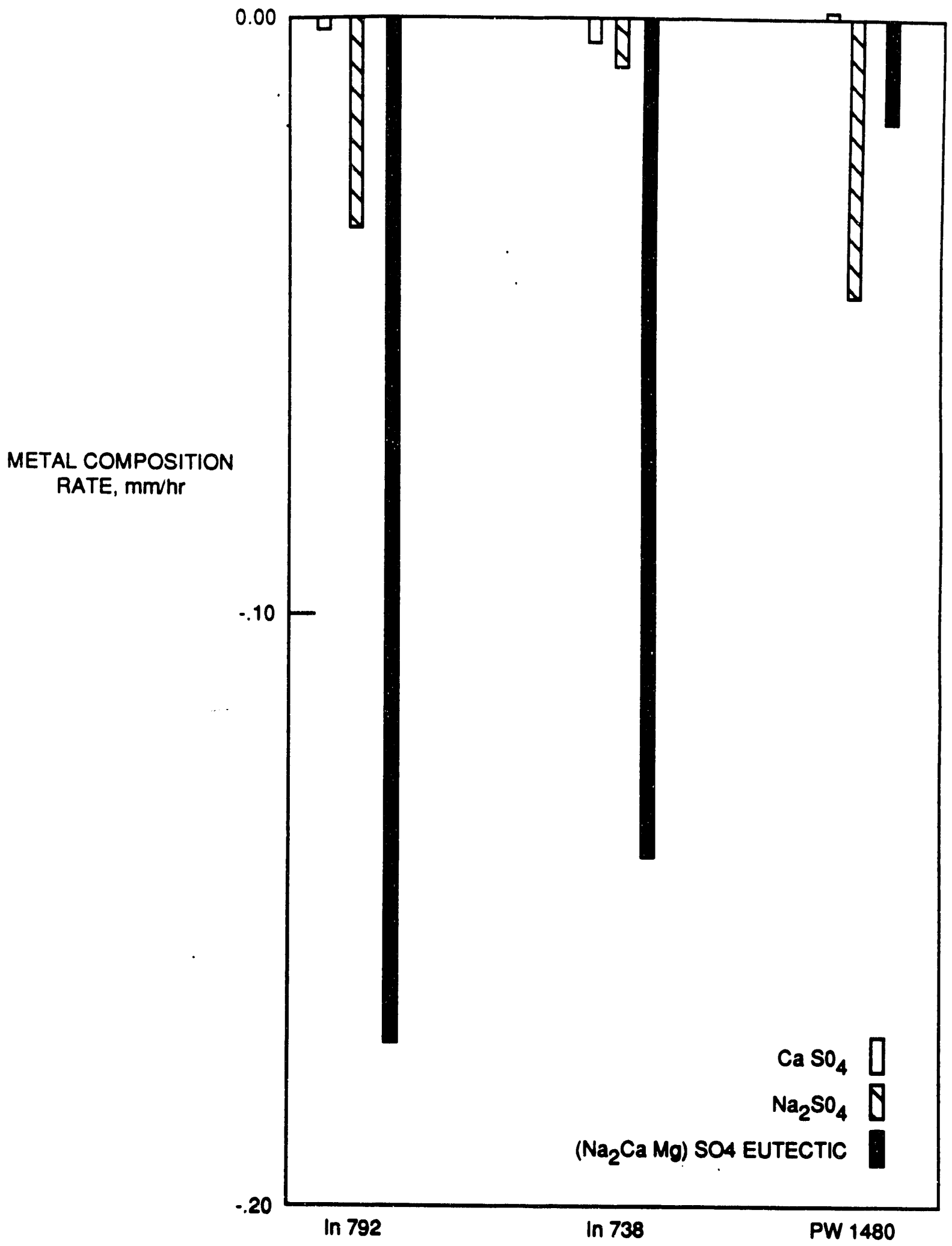



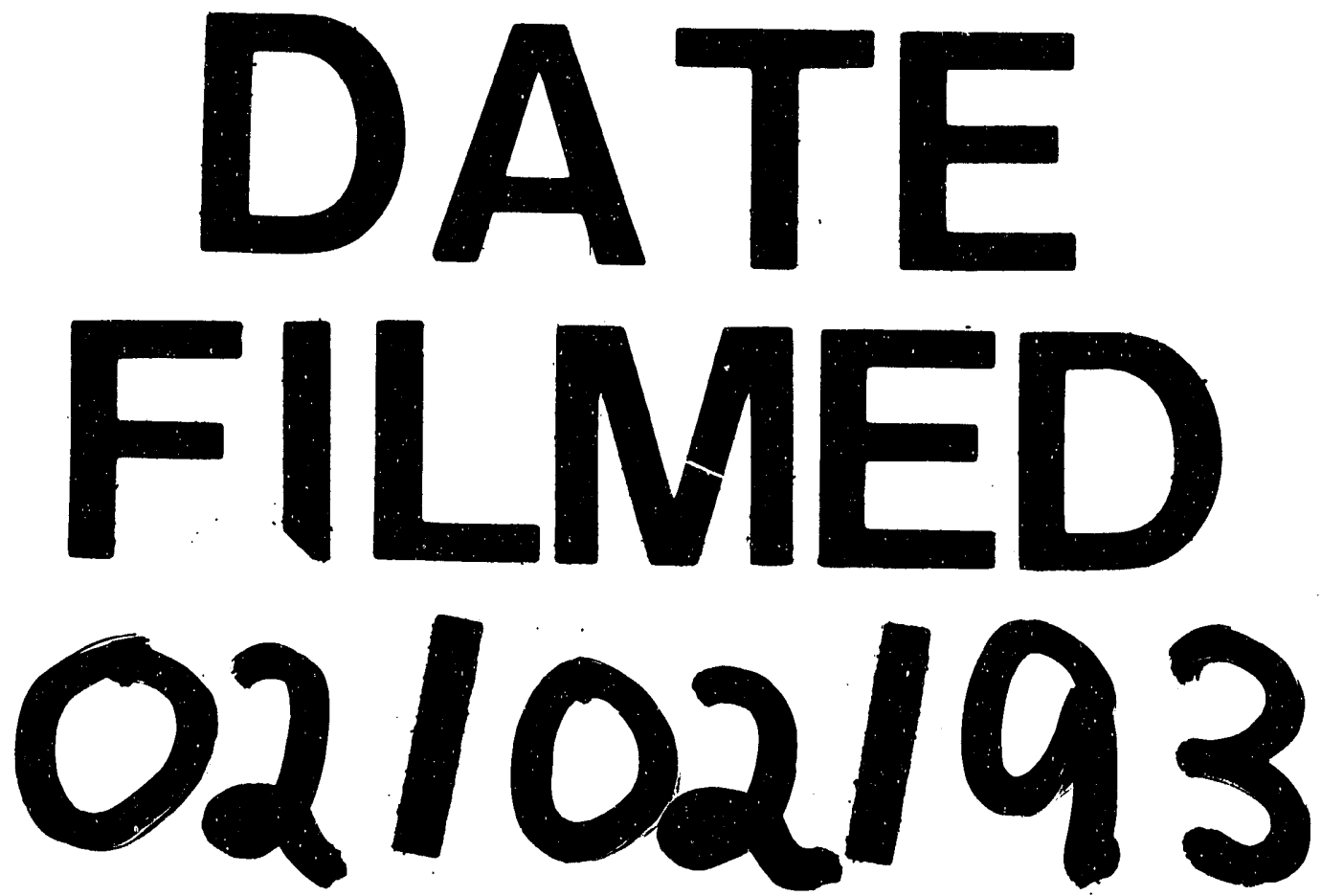
